\title{
RENEWABLE SOURCE HYBRID POWER GENERATION
}

\author{
Kirti G. More ${ }^{1}$, Ramling D. Patane ${ }^{2}$ \\ ${ }^{1}$ P.G. Student, Electronics Engineering Department, Terna Engineering College, Maharashtra, India \\ ${ }^{2}$ Associate Professor, General Science and Engineering Department, Terna Engineering College, Maharashtra, India
}

\begin{abstract}
This paper proposed an opportunity to utilize the revolutionary electrical power system in reference to information and communication technologies. Common sources for generation of power are utilized consisting of a solar panel and a wind turbine. Shifting generated energy in time as well as smoothing output of renewable energy is supported by energy storage devices. Hence energy generated will be stored in storage device in DC form. As when required, this energy is utilized by passing through an inverter to convert into AC. It can be connected to grid for continuous power supply.
\end{abstract}

Keywords: Solar Energy. Wind Energy, Controller, Inverter

\section{INTRODUCTION}

Renewable sources provide sustainable electric power and reduce emission of $\mathrm{CO}_{2}$. Common choices of renewable are hydro, wind, biomass (solid biomass, bio liquids and biogas), tidal stream, and photovoltaic (PV).Tidal power generator and wind turbines are used for variable speed turbines. Smart grid using PV and Wind turbine are best unified technology used for then power generation. Most technologies use either of the sources. This paper proposes the unified of PV and Wind turbine power generation.

\subsection{Necessity of Renewable Power Generation}

Renewable is the most intelligent method for power transfer dynamically to circuit and flows less through loaded circuit. Renewable technologies have proved to be clean energy sources with low impact on environment than that of conventional technology sources. Renewable energy plays important role in reducing global carbon emission and are long term infinite source of power. Renewable have proved financial support and encouraged policy measures heavily. Renewable sources like solar, wind, geothermal, hydropower and tidal energy also bio-fuels which are grown and harvested without fossil fuels. The most practical and plentiful available form of renewable is solar and wind energy

\subsection{SOLAR ENERGY}

The most common form of using renewable source in abundant is the solar energy which is directly converted into electricity by Photovoltaic (PV) and charge a battery or heating fluid for heat engine for generating electricity. As solar energy is non-constant in nature components like collector and storage are required for functioning of solar generator. The collector collects the radiated energy by converting it into other form and stores in storage device.

Fig.1 represents the block diagram of domestic PV system with main grid element. It consists of Maximum Power Point Tracking (MPPT), DC-AC inverter, a controller, output filter with a transformer [1].

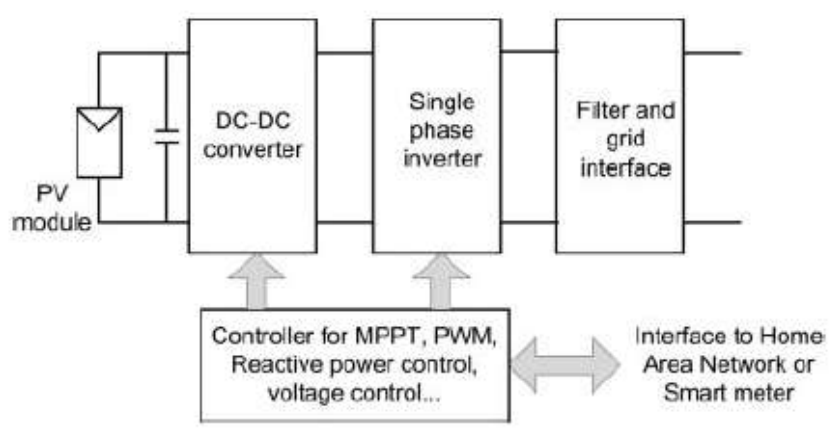

Fig.1 Block diagram of domestic PV System

Large numbers of photovoltaic cells are connected in series and parallel to form PV module.Fig.2 (a) represents characteristics of current versus voltage and power versus voltage of PV module. At knee point of voltage/current characteristics maximum output power of module is obtained [1].

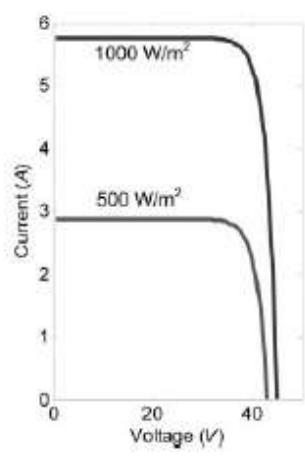

(a)

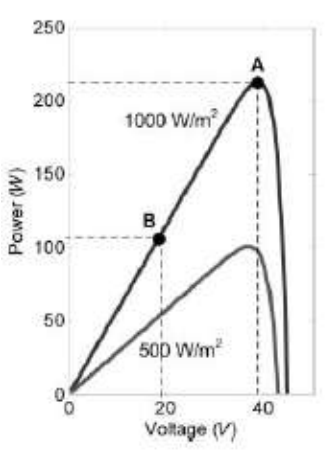

(b)
Fig.2 (a)Current/Voltage and (b)Power/voltage characteristics of a PV module

DC-DC Converters can be made of boost, push-pull, full bridge and fly back converter. The DC voltage is maintained constant by inverter control. As the operating condition and temperature of PV module changes the MPPT find 
continually maximum power extracted from DC voltage by the PV array. Hill climbing is known algorithm used by MPPT for digital controlling.

DC-DC converter inverts input DC voltage to $50 / 60 \mathrm{~Hz}$ AC. To reduce harmonics PWM switching technique is employed. The final stage also has filter to minimize harmonics fed to power system.

\subsection{WIND ENERGY}

Wind generators convert kinetic energy into mechanical and then into electrical energy. The aerodynamic properties of blades determine the efficiency by which the blades of turbine convert the wind power into kinetic energy.Fig.3 represents ideal power curve of a wind turbine[3]A.

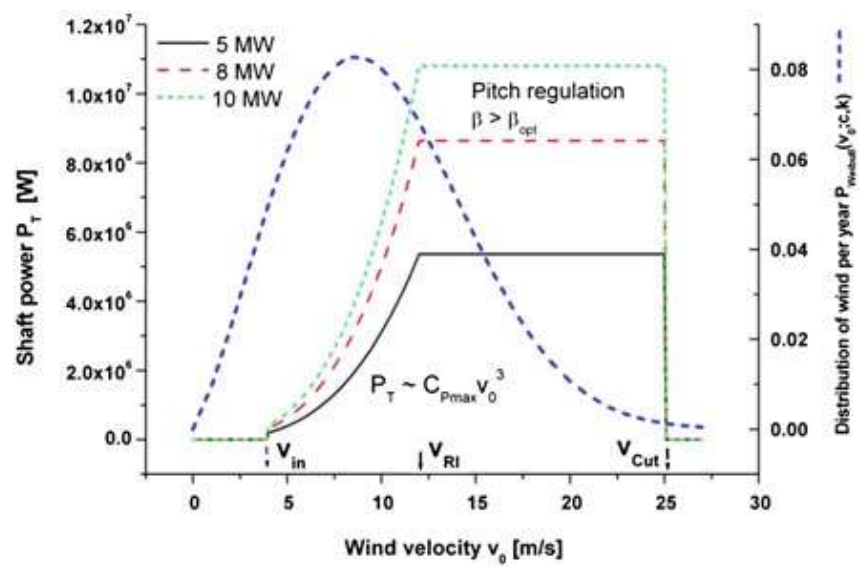

Fig.3 Ideal Power Curve for wind Turbine

Development of wind farms on and off shore are across the globe. Installing a wind turbine in sea is more expensive and more challenging where as offshore obtaining consistent and strong wind resource is possible resulting in reduced environmental impact. The offshore resources are variable speed turbines. To improve variable speed of turbines, different turbine design technologies are employed.

The aerodynamic forces generated by wind determine the performance aspect of wind turbine. The most common wind turbines are Horizontal Axis Wind Turbine (HAWT) while Vertical Axis Wind Turbine (VAWT) is used for special applications.

A vertical axis turbine with savonius rotor of drag driven type mechanism is employed to achieve high torque, which are cheap and easy to build. As represented in fig.4 these turbines have $\mathrm{S}$ shaped cross section savonius rotor [2].

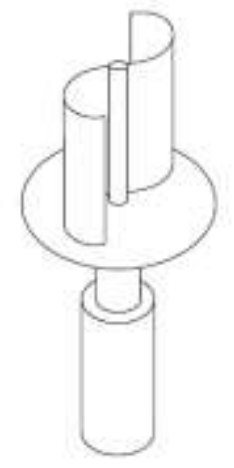

Fig. 4 Vertical Axis Wind Turbine with S shaped cross section savonius rotor

\section{PROPOSED SYSTEM}

The proposed system represented in fig. 5 is employed to generate power from both solar and wind as renewable sources simultaneously. The renewable sources are connected in parallel to the storage device. As the storage device gets power it charges until inverter is switched on converting DC power to AC. Hence used for various appliances. If supply power becomes less the storage device stops charging which can lead to lowering of battery life. Hence to avoid this damage charge controllers are employed to chop variable DC input power into constant DC Output.

For a renewable power generator, storage devices like Lead Acid Battery bank ensure reliability for standalone during sources have period of low generation as well once these are charged during peak hours of day batteries are switched off and load are run on renewable source. Inverters are the energy converting devices, for a renewable generator direct current (DC) from PV or Wind turbine is converted into (AC) and then to AC Loads and appliances. Inverters are employed to convert $\mathrm{DC}$ to $\mathrm{AC}$, hence are used for household appliances.

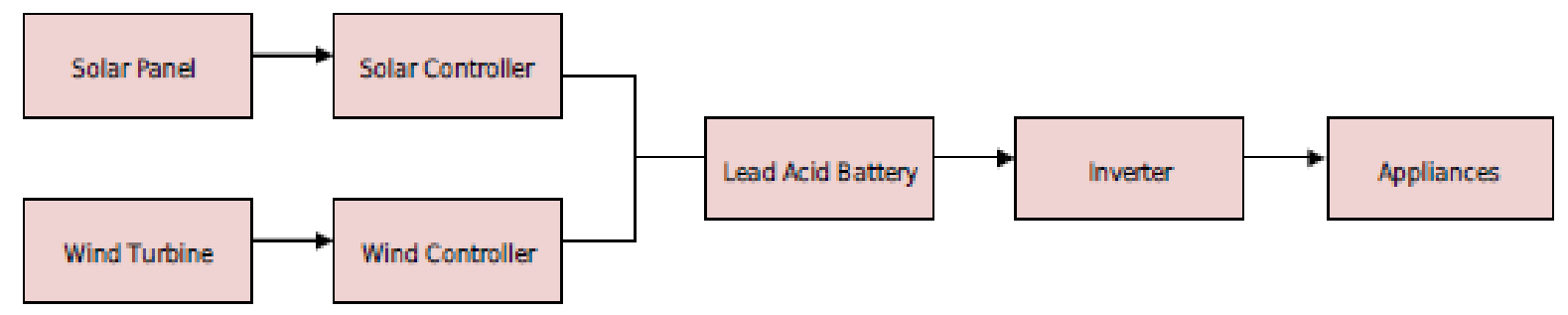

Fig.5 Block diagram of Proposed System

\section{INVERTER CIRCUIT}

The main components are as follows:

- Direct Transformer
- MOSFET Switch

- Capacitor

- Inductive Coil 
Direct transformers are step up transformers to step up the $\mathrm{AC}$ voltage to $230 \mathrm{~V}$ and protect against EMI due to atmospheric noise. MOSFETs provide soft switching with no switching and conduction losses. Voltage smoothening is done by capacitor which works as filters. Inductors are used as pre-transformer.

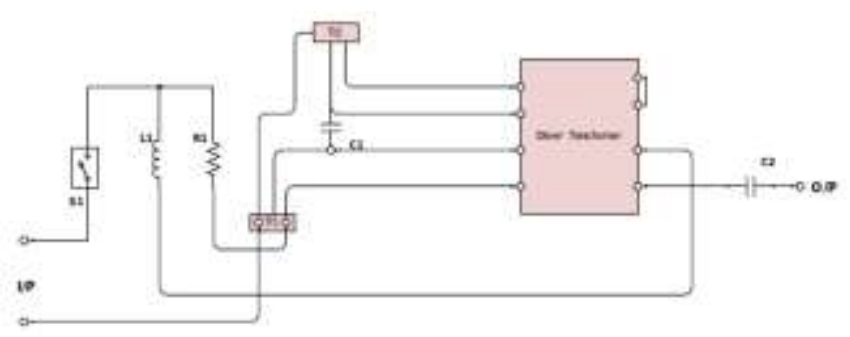

Fig.6 Inverter Circuit Diagram

\section{EXPERIMENTAL RESULT}

Observed voltage and current generated by solar and wind modules for a day,

Table I. Solar panel and wind turbine readings.

\begin{tabular}{|c|c|c|c|c|}
\hline \multirow{2}{*}{ Time } & \multicolumn{2}{|c|}{ Solar Panel } & \multicolumn{2}{c|}{ Wind Turbine } \\
\cline { 2 - 5 } & $\begin{array}{c}\text { Voltage } \\
(\mathrm{V})\end{array}$ & $\begin{array}{c}\text { Current } \\
(\mathrm{mA})\end{array}$ & $\begin{array}{c}\text { Voltage } \\
(\mathrm{V})\end{array}$ & $\begin{array}{c}\text { Current } \\
(\mathrm{mA})\end{array}$ \\
\hline 0900 & 10.5 & 9 & 0 & 0 \\
\hline 1200 & 11.5 & 10.6 & 0 & 0 \\
\hline 1500 & 12.2 & 11.9 & 1.3 & 0.6 \\
\hline 1800 & 10.2 & 9.4 & 0 & 0 \\
\hline
\end{tabular}

Table II. Battery charging analysis

\begin{tabular}{|c|c|c|}
\hline State of Charge (\%) & 12 V Battery & Volts per Cell \\
\hline 100 & 12.7 & 2.12 \\
\hline 60 & 12.20 & 2.03 \\
\hline 20 & 11.58 & 1.93 \\
\hline 0 & 10.5 & 1.75 \\
\hline
\end{tabular}

\section{CONCLUSION}

Developed system is good option for undeveloped rural areas as off-grid solution. It also provides stand alone operation by self sufficiently generating electricity. A timer based control circuit with sensor based controller can be used with solar tracker to increase efficiency of system.

\section{REFERENCES}

[1] SMART GRID TECHNOLOGY AND APPLICATIONS, Janaka Ekanayake, Cardiff University, UK Kithsiri Liyanage, University of Peradeniya, Sri Lanka, Jianzhong Wu, Cardiff University, UK, Akihiko Yokoyama University of Tokyo, Japan, Nick Jenkins, Cardiff University, UK
[2] Wind Power in Power Systems Edited by Thomas Ackermann, Royal Institute of Technology, Stockholm, Sweden.

[3] Wind Energy Conversion Systems Technology and Trends, S. M. Muyeen, Department of Electrical Engineering, The Petroleum Institute, Abu Dhabi, U.A.E. e-mail: muyeen0809@gmail.com.

[4] WIND ENERGY EXPLAINED Theory, Design and Application, Second Edition, J. F. Manwell and J. G. McGowan, Department of Mechanical and Industrial Engineering, University of Massachusetts, USA,A. L. Rogers, DNV - Global Energy Concepts, Washington, USA.

[5] A Glance at Renewable Energy Sources in India.

[6] Fundamentals of Photovoltaic Materials-National Solar Power Research Institute, Inc.

[7] Harvesting The Wind: The Physics of Wind TurbinesKira Grogg,2005.

[8] Wind Turbine Design Optimization-Michael Schmidt.

[9] The Case for Vertical Axis Wind Turbines-Terrance C. Sankar.

\section{BIOGRAPHIES}

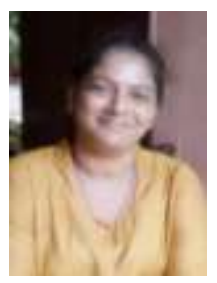

Mrs. Kirti G. More received her B.E Degree in Electrical Engineering from Sarder Patel College of Engineering, Mumbai, India in 2012 currently she is pursuing M.E in Terna Engineering College, Navi Mumbai, India, She has served 18 years working for academic field. Her research interest include Power electronics, industrial control and system.

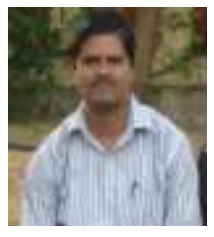

Prof. Ramling D. Patane has completed his post graduation in Electrical Power System. He served as an Associate professor in Terna Engineering Colleges since 24 years and has 1 year industrial experience. He presently works as a professor and HOD in the department of General Science and Engineering. His areas of interest are power system, Image processing, robotics, control systems and many more. As well as he has done 10 international and 8 national publications. 